\title{
Antibacterial activity of iron oxide nanoparticles synthesized by co- -precipitation technology against Bacillus cereus and Klebsiella pneumoniae
}

\author{
Shakeel Ahmed Ansari ${ }^{*}$, Mohammad Oves², Rukhsana Satar ${ }^{3}$, Anish Khan ${ }^{4}$, Syed Ismail Ahmad, \\ Mohammad Alam Jafri', Syed Kashif Zaidi', Mohammad Husein Alqahtani ${ }^{1}$ \\ ${ }^{1}$ King Abdulaziz University, Center of Excellence in Genomic Medicine Research, Jeddah-21589, Kingdom of Saudi Arabia \\ ${ }^{2}$ King Abdulaziz University, Center of Excellence in Environmental Studies, Jeddah-21418, Kingdom of Saudi Arabia \\ ${ }^{3}$ Ibn Sina National College for Medical Sciences, Department of Biochemistry, Jeddah-21418, Kingdom of Saudi Arabia \\ ${ }^{4}$ King Abdulaziz University, Center of Excellence for Advanced Materials Research, Jeddah-21589, Kingdom of Saudi Arabia \\ ${ }^{5}$ Ibn Sina National College for Medical Sciences, Physics Division, Basic Science Department, Jeddah-21418, Kingdom \\ of Saudi Arabia \\ "Corresponding author: e-mail: shakeel.cegmr@gmail.com
}

\begin{abstract}
The present study investigates the synthesis and characterization of iron oxide nanoparticles $\left(\mathrm{Fe}_{3} \mathrm{O}_{4}-\mathrm{NPs}\right)$ for their antibacterial potential against Bacillus cereus and Klebsiella pneumonia by modified disc diffusion and broth agar dilution methods. DLS and XRD results revealed the average size of synthesized $\mathrm{Fe}_{3} \mathrm{O}_{4}$-NPs as $24 \mathrm{~nm}$ while XPS measurement exhibited the spin-orbit peak of Fe $2 \mathrm{p}_{3 / 2}$ binding energy at $511 \mathrm{eV} . \mathrm{Fe}_{3} \mathrm{O}_{4}-\mathrm{NPs}$ inhibited the growth of $\mathrm{K}$. pneumoniae and B. cereus in both liquid and soild agar media, and displayed $26 \mathrm{~mm}$ and $22 \mathrm{~mm}$ zone of inhibitions, respectively. $\mathrm{MIC}$ of $\mathrm{Fe}_{3} \mathrm{O}_{4}$-NPs was found to be $5 \mu \mathrm{g} / \mathrm{mL}$ against these strains. However, MBC for these strains was observed at $40 \mu \mathrm{g} / \mathrm{mL}$ concentration of $\mathrm{Fe}_{3} \mathrm{O}_{4}$-NPs for exhibiting 40-50\% loss in viable bacterial cells and $80 \mu \mathrm{g} / \mathrm{mL}$ concentration of $\mathrm{Fe}_{3} \mathrm{O}_{4}-\mathrm{NPs}$ acted as bactericidal for causing 90-99\% loss in viability. Hence, these nanoparticles can be explored for their additional antimicrobial and biomedical applications.
\end{abstract}

Keywords: antibacterial activity, co-precipitation, iron oxide nanoparticles, Klebsiella pneumoniae, physicochemical characterization.

Abbreviations: $\mathrm{Fe}_{3} \mathrm{O}_{4}-\mathrm{NPs}$, iron oxide nanoparticles; $\mathrm{MBC}$, minimum bactericidal concentration; MIC, minimum inhibitory concentration; XPS; X-ray photoelectron spectroscopy.

\section{INTRODUCTION}

Antibiotics have been a mainstay of human health. They have been extensively used in clinics to treat respiratory tract infections, urinary tract infections, gastrointestinal infections and infections of nervous system ${ }^{1}$. However, the emergence of multidrug resistant bacterial strains such as Methicillin resistant staphylococcus aureus (MRSA), Vancomycin resistant staphylococcus aureus (VRSA) and New Delhi metallo-beta-lactamase (NDM) harboring Gram-negative bacteria, has severely compromised their effectiveness in the clinics. Therefore, novel antibiotics with newer mechanism of action are urgently needed to treat infections caused by MDR-bacterial strains. Numerous nanoparticle have been reported to possess considerable activity against MDR-bacterial strains ${ }^{2-5}$ including resistant Enterobacteriaceae (E. coli, K. pneumoniae), non-fermenters (Acinetobacter baumanii, Pseudomonas aeruginosa) and acid-fast bacteria (Mycobacterium tuberculosis) as well as resistant Gram-positives such as vancomycin resistant Enterococci and methicillin-resistant Staphylococcus aureus ${ }^{5,6}$. Furthermore, new strategies like surface modification of nanoparticles are being explored to enhance their potency against pathogenic MDR bacterial strains ${ }^{7}$.

Klebsiella pneumoniae is an encapsulated Gram-negative rod-shaped facultative anaerobe belonging to Enterobacteriaceae family which causes pneumonia, bloodstream infections, surgical site infections and meningitis ${ }^{8}$. The NDM carrying Klebsiella pneumoniae stains are frequently involved in nosocomial (hospital-acquired) and common public infections. These strains are resistant to almost every antibiotic and infections caused by them are extremely difficult to treat. Moreover, Klebsiella pneumoniae strains have the potential to produce slime, which facilitates the adhesion and formation of biofilms on implantable devices via non-specific interactions like electrostatic, dipole-dipole, H-bond, hydrophobic and vander Waals forces ${ }^{9},{ }^{10}$. Formation of such biofilms enhances the bacterial resistance by preventing antibiotic action. Bacillus cereus is Gram positive, rod shaped bacterium, widely distributed in diverse environments ${ }^{\mathbf{1 1}}$. It is commonly involved in food poisoning causing severe diarrhea. However, in immunocompromised patients it is associated with wound infections, bacteremia, septicaemia, endocarditis, meningitis and pneumonia as well as respiratory infections which may be life threatening ${ }^{\mathbf{1 2}}$.

Iron oxides are abundantly distributed in the earth crust and have been frequently used in a wide variety of biomedical and biotechnological applications. Nanoparticles synthesized from these oxides have also been employed for diagnostic imaging (magnetic resonance imaging), cancer treatment (magnetic hyperthermia, thermal ablation), scale-up bioseparation processes and biosensing-based applications ${ }^{13},{ }^{14} \cdot \mathrm{Fe}_{3} \mathrm{O}_{4}$-NPs-based biomedical applications have received considerable attention due to their ease of laboratory synthesis, cost effectiveness, physical and chemical stability, as well as biocompatibility and environmental safety ${ }^{15-17}$. Therefore, $\mathrm{Fe}_{3} \mathrm{O}_{4}$-NPs may be reasonable candidates for their potential use as antibacterial therapy. The current study was undertaken to synthesize $\mathrm{Fe}_{3} \mathrm{O}_{4}$-NPs by co-precipitation method for evaluating their antimicrobial activity against Klebsiella pneumoniae and Bacillus cereus. 


\section{EXPERIMENTAL METHODS}

\section{Materials}

Ferrous chloride tetrahydrate $\left(\mathrm{FeCl}_{2} \cdot 4 \mathrm{H}_{2} \mathrm{O}\right)$, ferric chloride hexahydrate $\left(\mathrm{FeCl}_{3} \cdot 6 \mathrm{H}_{2} \mathrm{O}\right)$ and sodium hydroxide $(\mathrm{NaOH})$ were obtained from Sisco Research Laboratories Pvt. Ltd. (Mumbai, India) and used as such without further purification. The bacterial culture media, nutrients broth and nutrient agar were purchased from Hi Media, Mumbai, India. The deionized water was used for the preparation of reagents and culture media. The bacterial strains Klebsiella pneumoniae and Bacillus cereus used in this study were obtained from local hospital.

\section{Synthesis of $\mathrm{Fe}_{3} \mathrm{O}_{4}$-NPs}

The co-precipitation method was used for the synthesis of $\mathrm{Fe}_{3} \mathrm{O}_{4}$-NPs. Briefly, ferric chloride $(200 \mathrm{mg}$ ) and ferrous chloride $(100 \mathrm{mg})$ were dissolved in deionized water $(25$ $\mathrm{mL}$ ) under continuous stirring and heated at $60^{\circ} \mathrm{C}$. The solution was bubbled with Argon for preventing unwanted oxidation. Subsequently, 2.5 M NaOH (15 mL) was injected at $60^{\circ} \mathrm{C}$ and the reaction was continued under similar incubation conditions for 20 minutes before the flask was removed from heating and stirring. Magnetic field was applied to separate $\mathrm{Fe}_{3} \mathrm{O}_{4}$-NPs formed as black precipitate and obtained $\mathrm{Fe}_{3} \mathrm{O}_{4}-\mathrm{NP}$ were thoroughly washed with distilled water and finally transferred to an oven at $100^{\circ} \mathrm{C}$ for overnight drying. Dried power of $\mathrm{Fe}_{3} \mathrm{O}_{4}$-NPs was used for subsequent analysis and physical characterization.

\section{Physico-chemical characterization of $\mathrm{Fe}_{3} \mathrm{O}_{4}-\mathrm{NPs}$}

The synthesized $\mathrm{Fe}_{3} \mathrm{O}_{4}$-NPs were subjected for recording FTIR spectrum at $500-4000 \mathrm{~cm}^{-1}$ by using Interspec 2020 model FTIR instrument (USA). The dynamic light scattering characterization was carried out in a Malvern Zetasizer Nano ZS while their structural characterization was done by analyzing XRD pattern at room temperature with the help of Rigaku-Miniflex X-ray diffractometer using $\mathrm{CuK}_{\alpha}(\lambda=1.54056 \AA)$ radiations as X-ray source in $2 \mathrm{q}$ range from $20^{\circ}$ to $80^{\circ}$ with scan rate of $2^{\circ} / \mathrm{min}$. For XPS analysis of $\mathrm{Fe}_{3} \mathrm{O}_{4}$-NPs, we used a Thermo Scientific K-Alpha KA1066 spectrometer with monochromatic AlK $\alpha$ $\mathrm{X}$-ray radiation as excitation source and beam-spot size fixed at $300 \mu \mathrm{m}$. The spectral recording was performed at $200 \mathrm{eV}$ (pass energy) in the fixed analyzer transmission mode whereas scanning was carried out at pressures of less $10^{-8}$ Torr.

\section{Antibacterial assay}

Antibacterial test of $\mathrm{Fe}_{3} \mathrm{O}_{4}$-NPs was performed against Klebsiella pneumonia and Bacillus cereus bacterial stains. The inoculum of test organisms was prepared by inoculating flasks containing sterilized $25 \mathrm{~mL}$ of nutrient broth with the isolated colonies of test organisms and incubating them at $37^{\circ} \mathrm{C}$ overnight on an orbital shaker incubator. The overnight cultures were diluted with fresh nutrient broth and spread onto solid nutrients agar plates with the help of sterilized glass spreader or cotton swab. The plates were left to dry for $15 \mathrm{~min}$ and then $8 \mathrm{~nm}$ wells were bored in each plate with the help of a sterilized borer. The different concentrations of $\mathrm{Fe}_{3} \mathrm{O}_{4}$-NPs aqueous suspension were loaded in the wells of each plate and one well served as a control for standard antibiotics. Then, each well was sealed by molten agar $(0.8 \%)$ to prevent the leakage of loaded compounds in base of well. The plates were incubated at $37^{\circ} \mathrm{C}$ for 24 hours. Following incubation, the developed zone of inhibition of bacterial growth around the well was recorded.

Determination of minimum inhibition concentration (MIC) and minimum bactericidal concentration (MBC)

Klebsiella pneumonia and Bacillus cereus overnight cultures were diluted with nutrient broth in order to obtain a final inoculum of $1 \times 10^{6} \mathrm{CFU} / \mathrm{mL}$. Stock solution of $\mathrm{Fe}_{3} \mathrm{O}_{4}$-NPs for MBC and MIC were separately prepared. Different concentrations of $\mathrm{Fe}_{3} \mathrm{O}_{4}$-NPs were added to the tubes containing test organism. Positive and negative controls were also prepared separately with and without $\mathrm{Fe}_{3} \mathrm{O}_{4}$-NPs and organisms, respectively. The tubes were incubated at $37^{\circ} \mathrm{C}$ in an incubator overnight. Turbidity was checked for analyzing the growth of organism in presence of compound. Lowest concentration which inhibited the growth of organism indicated MIC whereas $\mathrm{MBC}$ was considered as a concentration that caused 2-3 log (90-99\%) reduction in CFU compared to starting inoculum. All MIC and MBC experiment were performed in duplicate.

\section{Statistical analysis}

For antibacterial activity, the size of growth inhibition zones was expressed in terms of mean value \pm standard error and a $\mathrm{P}$ value lower than 0.05 was taken as a significant value.

\section{RESULTS AND DISCUSSION}

\section{Selection of $\mathrm{Fe}_{3} \mathrm{O}_{4}$-NPs}

We selected iron oxide nanoparticles because of their relatively better safety and superior biological compatibility. These nanoparticles have been reported to have lower toxicity due to the presence of 4 unpaired electrons in $3 \mathrm{~d}$ shell of $\mathrm{Fe}^{2+}$ ions and 5 unpaired electrons of $3 \mathrm{~d}$ shell of $\mathrm{Fe}^{3+}$ which facilitate strong magnetic moment. Therefore, the crystals formed by these ions are ferromagnetic or ferrimagnetic in nature which provides them better biocompatibility and lower toxicity ${ }^{\mathbf{1 3}, 15,18}$. The co-precipitation method was adopted due to the simplicity of their synthesis in aqueous solution. This method involves precipitation of $\mathrm{Fe}^{2+}$ and $\mathrm{Fe}^{3+}$ ions (mixed in molar ratio of $1: 2$ ) into $\mathrm{Fe}_{3} \mathrm{O}_{4}$ in a basic solution (ammonium hydroxide, potassium hydroxide, sodium hydroxide, $\mathrm{pH}$ 8-14). However, it has been reported that size, morphology and magnetic properties of nanoparticles synthesized by co-precipitation method vary significantly. In the current study, $\mathrm{Fe}_{3} \mathrm{O}_{4}$-NPs synthesis was carried out in presence of $\mathrm{NaOH}$ which yielded nanoparticle of $24 \mathrm{~nm}$ average size.

Furthermore, for wider bioapplications of iron oxide NPs, they should be highly dispersed in aqueous phase and biocompatible with negligible toxicity. These properties can be achieved by adopting co-precipitation method using multifunctional water-soluble polymers as capping ligands ${ }^{19}$. Hence, the method of synthesis utilized here for obtaining $\mathrm{Fe}_{3} \mathrm{O}_{4}$-NPs imparts uniformity in size and 
morphology to them. Moreover, due to their higher saturation magnetization, they could be manipulated in dispersed state with the use of an external magnet for extending their scope in various biomedical applications.

\section{Physico-chemical characterization of $\mathrm{Fe}_{3} \mathrm{O}_{4}$-NPs}

The infrared spectrum of $\mathrm{Fe}_{3} \mathrm{O}_{4}$-NPs in the range of $500-4000 \mathrm{~cm}^{-1}$ was carried out to identify the chemical bonds and functional groups present in it. Fig 1 demonstrated the $\mathrm{O}-\mathrm{H}$ stretching vibration in $\mathrm{O}-\mathrm{H}$ groups as suggested by the large broad band at $3625 \mathrm{~cm}^{-1}$. The

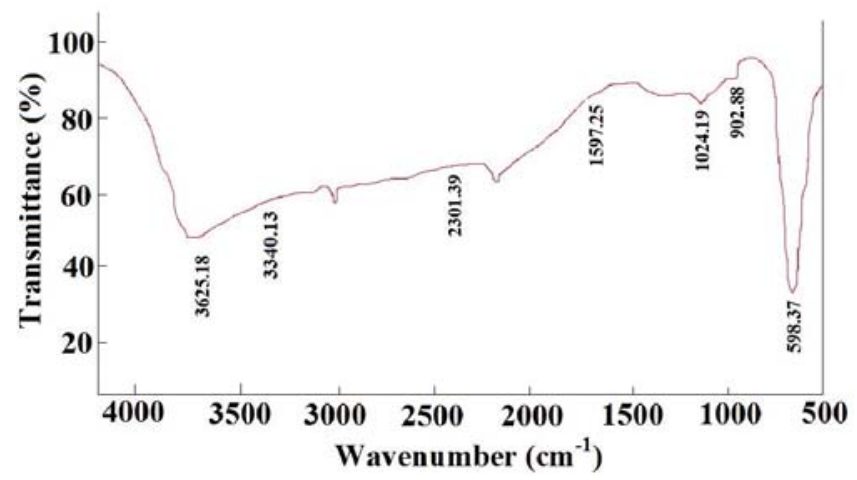

Figure 1. FTIR spectra of $\mathrm{Fe}_{3} \mathrm{O}_{4}$-NPs

absorption peaks around $1597 \mathrm{~cm}^{-1}$ correspond to the asymmetric and symmetric bending vibration of $\mathrm{C}=\mathrm{O}$ while the absorption peak around $1024 \mathrm{~cm}^{-1}$ is ascribed to polyvinylpyrrolidone. The strong band observed below $700 \mathrm{~cm}^{-1}$ was produced by $\mathrm{Fe}-\mathrm{O}$ stretching mode while the $\mathrm{Fe}-\mathrm{O}$ stretching mode band of $\mathrm{Fe}_{3} \mathrm{O}_{4}$ was observed at $598 \mathrm{~cm}^{-120}$. The average mean size of synthesized $\mathrm{Fe}_{3} \mathrm{O}_{4}$ -NPs was in the range of 20-25 nm (Fig. 2). Figure 3

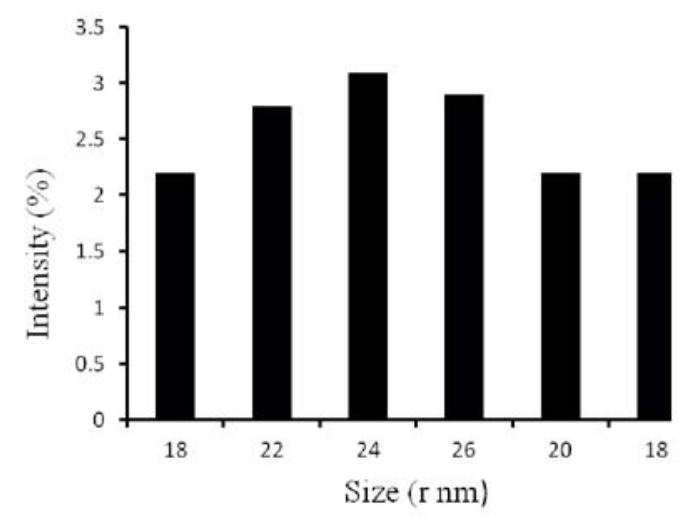

Figure 2. Differential light scattering of $\mathrm{Fe}_{3} \mathrm{O}_{4}-\mathrm{NPs}$

suggested that the size of the synthesized $\mathrm{Fe}_{3} \mathrm{O}_{4}$-NPs were of $24 \mathrm{~nm}$. The results showed the spinel phase structure of magnetite which is in agreement with the standard XRD for magnetite nanoparticles synthesized by other methods ${ }^{13},{ }^{18}$. X-ray photoelectron spectroscopy (XPS) is frequently used for elucidating numerous chemical parameters including the presence of various elements, empirical-formula, and chemical and electronic states of the elements constituting the test material. XPS spectra are obtained by irradiating test materials with a beam of X-rays and determining the kinetic energy as well as the number of electrons released from the top of the material surface ${ }^{21,22}$. We used XPS measure-

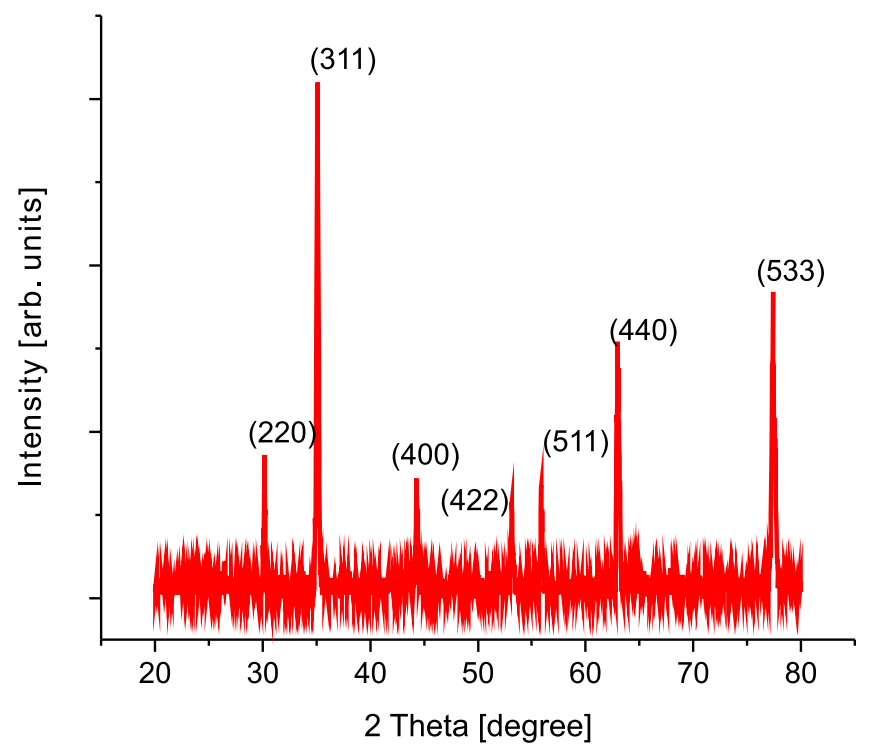

Figure 3. XRD analysis of $\mathrm{Fe}_{3} \mathrm{O}_{4}$-NPs

ments in order to find out the chemical states of iron and oxygen in $\mathrm{Fe}_{3} \mathrm{O}_{4}$-NPs. XPS spectrum of $\mathrm{Fe}_{3} \mathrm{O}_{4}$-NPs is presented in Figure 4. The spin-orbit peak of the Fe $2 p_{3 / 2}$ binding energy observed at $511 \mathrm{eV}$ (Fig. $4 \mathrm{~b}$ ) is fully concordant with the standard reference data for iron ${ }^{23}$. A distinct peak observed at $532.6 \mathrm{eV}$ in $\mathrm{O} 1 \mathrm{~s}$ spectrum (Fig. 4c) indicated the presence of oxygen (i.e. $\mathrm{O}_{2}^{-}$) in the $\mathrm{Fe}_{3} \mathrm{O}_{4}-\mathrm{NPs}^{24}$. Therefore, it can be concluded that the synthesized $\mathrm{Fe}_{3} \mathrm{O}_{4}$-NPs contains only two elements and is free from other impurities.

\section{Antibacterial activity of $\mathrm{Fe}_{3} \mathrm{O}_{4}$-NPs}

Resistance to currently used antibiotics is a serious public health problem nowadays. The prevalence of bacterial isolates with resistance to multiple antibiotics has increased significantly in both hospitals as well as in community. Novel antibiotics are needed to effectively treat infections caused by these resistant strains. The nanoparticles have been extensively evaluated for their potential as suitable antibacterial candidates which may be developed as antibacterial therapy for clinical application. Numerous organic and inorganic nano-materials as well as a large number of nanoparticles have been synthesized for this purpose of providing safe and effective antimicrobial agents against MDR bacterial strains. $\mathrm{Fe}_{3} \mathrm{O}_{4}-\mathrm{NPs}$ exhibit considerable antibacterial effects because of their specific features including their size and larger surface area which facilitates their interactions with critically important biomolecules inside the bacterial cell. In the current study, $\mathrm{Fe}_{3} \mathrm{O}_{4}$-NPs demonstrated significant antibacterial activity against both Bacillus cereus and Klebsiella pneumoniae strains. The exact molecular mechanisms of antibacterial action of iron oxide nanoparticles are less understood. However, it is possible that they exert their antibacterial action through the interactions of ferric ions with the proteins and DNA thereby causing the conformational changes in protein structure and DNA molecule, which ultimately leads to the mortality of bacterial cell. However, generation of reactive oxygen species (ROS) has also been implicated as one of the possible mechanism of antibacterial action of iron nanoparticles. These nanoparticles also displayed a bactericidal action against Klebsiella pneumoniae and Bacillus cereus which 

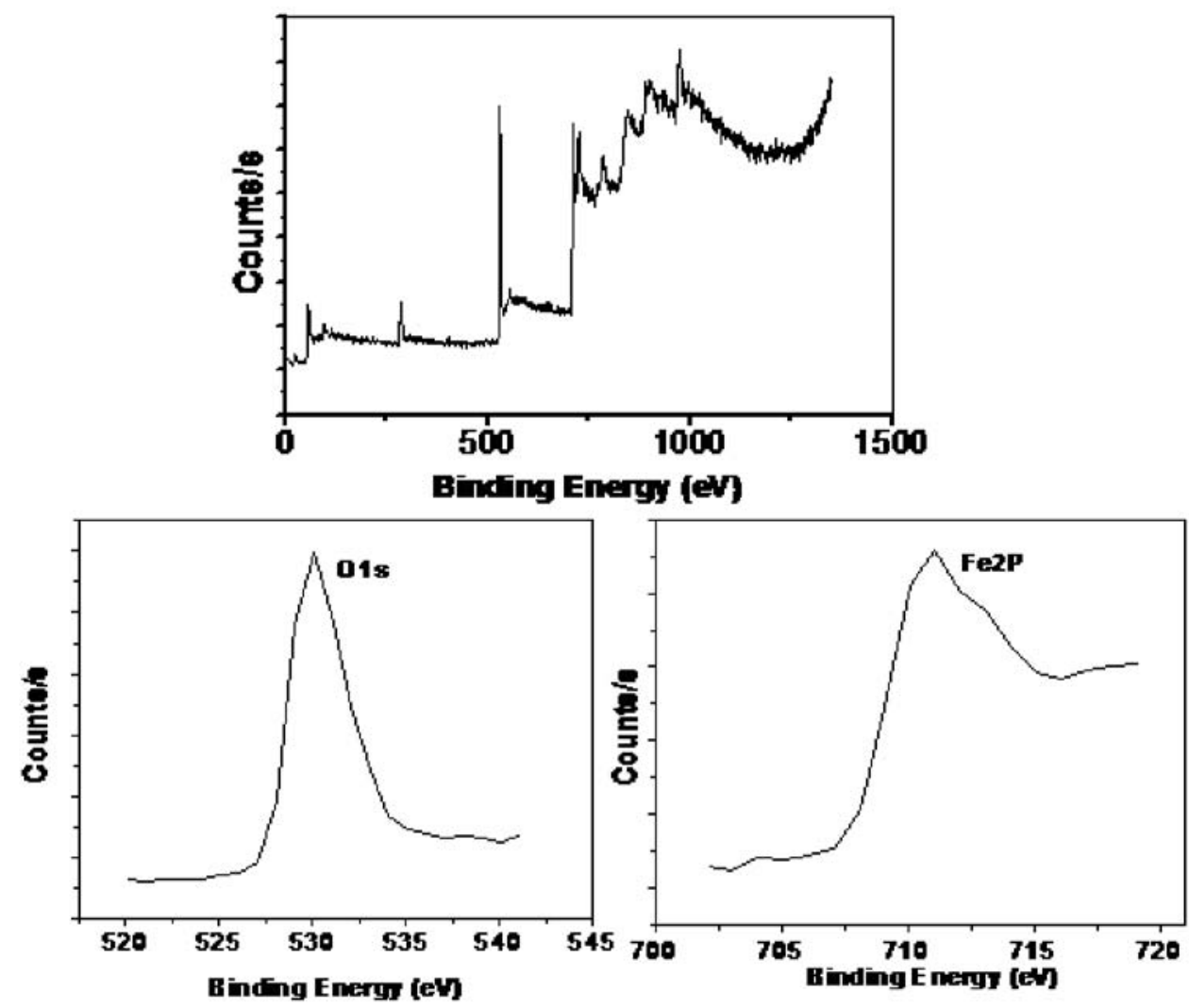

Figure 4. X-ray photoelectron spectroscopy of $\mathrm{Fe}_{3} \mathrm{O}_{4}$-NPs

is an important attribute from pharmacodynamic point of view as bactericidal antibiotics completely eradicate bacterial cells which reduces chances of emergence of resistant bacterial strains.

In our investigation, $\mathrm{Fe}_{3} \mathrm{O}_{4}$-NPs were employed to evaluate their bactericidal potential for Klebsiella pneumonia and Bacillus cereus (Fig. 5). They showed antibacterial activity in a concentration dependent manner with higher concentrations exhibiting larger zones of inhibition. The zone of inhibition was 15 and $13 \mathrm{~mm}$ at $40 \mu \mathrm{g} / \mathrm{well}$ concentration of $\mathrm{Fe}_{3} \mathrm{O}_{4}$-NPs against Klebsiella pneumoniae and Bacillus cereus respectively. However, at higher concentration of $80 \mu \mathrm{g} / \mathrm{well}$, the zone size was increased to 26 and $22 \mathrm{~mm}$ (Fig. 6). We also determined MIC values of $\mathrm{Fe}_{3} \mathrm{O}_{4}-\mathrm{NPs}$ against these strains. MIC value of $\mathrm{Fe}_{3} \mathrm{O}_{4}-\mathrm{NPs}$ was found to be $5 \mu \mathrm{g} / \mathrm{mL}$ for Klebsiella pneumoniae and Bacillus cereus. Further, we also tried to find out whether antibacterial action of $\mathrm{Fe}_{3} \mathrm{O}_{4}$-NPs was bacteriostatic or bactericidal. MBC experiments were performed in liquid broth media and results were obtained in terms of $\%$ viability of bacterial cells following $24 \mathrm{~h}$ exposure to different concentrations of $\mathrm{Fe}_{3} \mathrm{O}_{4}$-NPs (Fig. 7). The significant killing of Klebsiella pneumoniae and Bacillus cereus cells was observed at 40

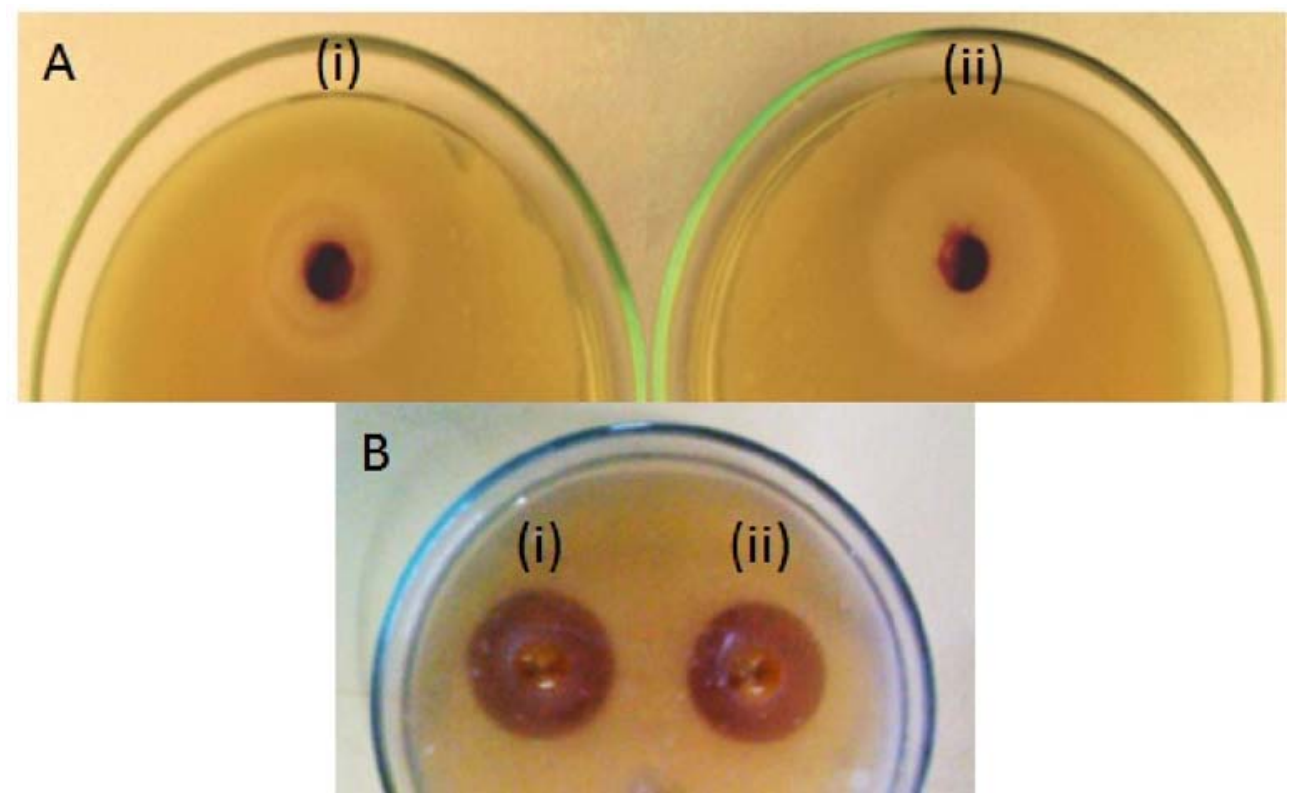

Figure 5. Antimicrobial potential of synthesized $\mathrm{Fe}_{3} \mathrm{O}_{4}$-NPs doses (i) 80 and (ii) $60 \mu \mathrm{g} /$ well on solid agar media (A) K. pneumonia and (B) B. cereus 


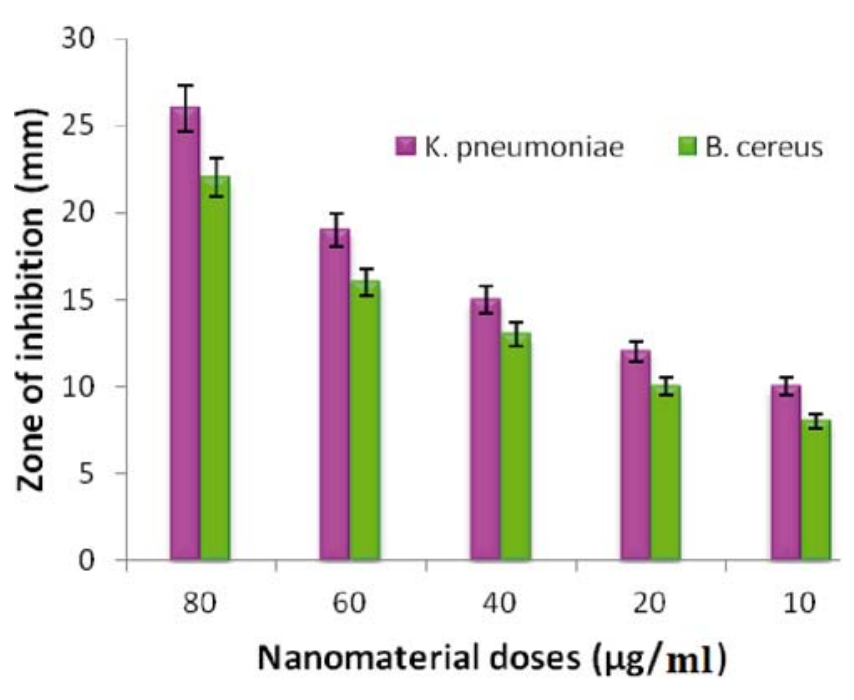

Figure 6. Zone of inhibition pattern of different dose against Gram negative $K$. pneumonia and Gram positive $B$. cereus

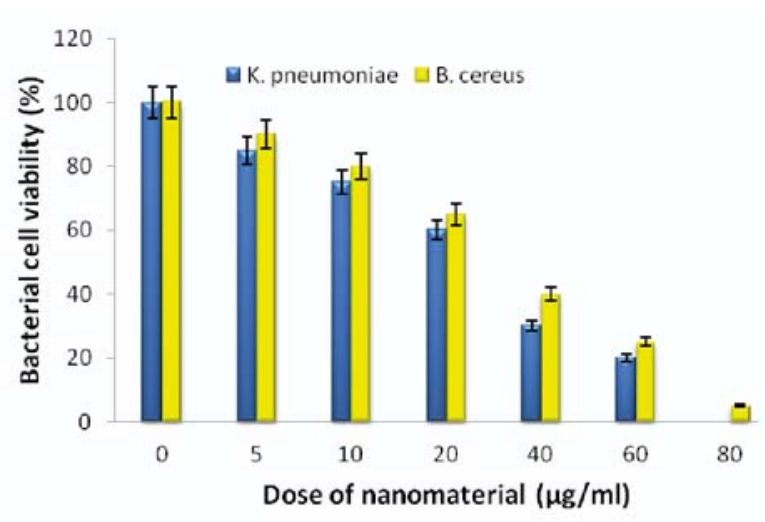

Figure 7. Viability of bacterial cell in presence of different dose of nanomaterials in liquid medium

$\mu \mathrm{g} / \mathrm{mL}$ exhibiting around $40-50 \%$ loss in viable bacterial cells whereas $80 \mu \mathrm{g} / \mathrm{mL}$ concentration of $\mathrm{Fe}_{3} \mathrm{O}_{4}$-NPs was found to be bactericidal causing 90-99\% loss in viability. Mechanistically, these nanoparticles may cause damage to bacterial cell membrane either directly binding to lipid molecules or through the release of ROS which may cause intracellular damage leading to a powerful bactericidal action. Similar mechanism has been proposed for positively charged nanoparticles against various bacterial strains $\mathrm{s}^{25-27}$. However, exact molecular nature of antibacterial action of $\mathrm{Fe}_{3} \mathrm{O}_{4}$-NPs remains to be clearly elucidated.

\section{CONCLUSION}

The nanoparticles have great potential as nanomedicine for the treatment of various bacterial diseases. The ultra-small size of nanoparticles may facilitate their diffusion through porin channels of bacterial cell wall to exert their antibacterial action via destruction of the membrane integrity and intracellular damage. However, robust preclinical studies are required to establish their potential as antibacterial agents as well as to demonstrate sound proof of concept in the animal models of infection.

\section{ACKNOWLEDGEMENT}

This article was funded by the Deanship of Scientific Research (DSR), King Abdulaziz University, Jeddah. The authors, therefore, acknowledge with thanks DSR technical and financial support.

\section{CONFLICT OF INTEREST}

We have no conflict of interest to declare.

\section{LITERATURE CITED}

1. Singh, R., Smitha, M.S. \& Singh, S.P. (2014). The role of nanotechnology in combating multi-drug resistant bacteria. J. Nanosci. Nanotechnol. 14(7), 4745-4756. DOI: 10.1166/ jnn.2014.9527.

2. Stubbings, W. \& Labischinski, H. (2009). New antibiotics for antibiotic-resistant bacteria. Biol. Rep. 17(1) 40-46. DOI: 10.3410/B1-40.

3. Patrascu, J.M., Nedelcu, I.A., Sonmez, M., Ficai, D., Ficai, A. \& Vasile, B.S. (2015). Composite scaffolds based on silver nanoparticles for biomedical applications. J. Nanomat. 8 pages. DOI: http://dx.doi.org/10.1155/2015/587989.

4. Caamano, M.A., Carrillo-Morales, M. \& Olivares-Trejo, J.J. (2016). Iron oxide nanoparticle improve the antibacterial activity of erythromycin. J. Bacteriol. Parasitol. 7(4), 267-270. DOI: 10.4172/2155-9597.1000267.

5. Kalishwaralal, K., Barathmanikanth, S., Pandian, S.R.K., Deepak, V. \& Gurunathan, S. (2010). Silver nanoparticles impede the biofilm formation by Pseudomonas aeruginosa and Staphylococcus epidermidis. Coll. Surf. B: Biointerf. 79(2), 340-344. DOI: 10.1016/j.colsurfb.2010.04.014.

6. Mihu, M.R., Sandkovsky, U., Han, G., Friedman, J.M., Nosanchuk, J.D. \& Martinez, L.R. (2010). The use of nitric oxide releasing nanoparticles as a treatment against Acinetobacter baumannii in wound infections. Virulence 1(2), 62-67. DOI: 10.4161/viru.1.2.10038.

7. Satar, R., Syed, I.A., Rasool, M., Pushparaj, P.N. \& Ansari, S.A. (2016). Investigating the antibacterial potential of agarose nanoparticles synthesized by nanoprecipitation technology. Pol. J. Chem. Technol. 18(2), 9-12. DOI: https:// doi.org/10.1515/pjct-2016-0022.

8. Fang, C.T., Lai, S.Y., Yi, W.C., Hsueh, P.R., Liu, K.L. \& Chang, S.C. (2007). Klebsiella pneumoniae genotype K1: an emerging pathogen that causes septic ocular or central nervous system complications from pyogenic liver abscess. Clin. Infect. Dis. 45(3), 284-290. DOI: 10.1086/519262.

9. Donlan, R.M. (2001). Biofilms and device-associated infections. Emer. Inf. Dis. 7(2), 277-281. DOI: 10.3201/ eid0702.700277.

10. Jagnow, J. \& Clegg, S. (2003). Klebsiella pneumoniae MrkD-mediated biofilm formation on extracellular matrix and collagen-coated surfaces. Microbiology 149(9), 2397-2405. DOI: 10.1099/mic.0.26434-0.

11. Ash, C., Farrow, J.A., Dorsch, M., Stackenbrandt, E. \& Collins, M.D. (1991). Comparative analysis of Bacillus anthracis, Bacillus cereus, and related species on the basis of reverse transcriptase of 16S rRNA. Int. J. Syst. Bacteriol. 41(3), 343-346. DOI: 10.1099/00207713-41-3-343.

12. Bottone, E.J. (2010). Bacillus Cereus, a volatile human pathogen. Clin. Microbiol. Rev. 23(2), 382-398. DOI: 10.1128/ CMR.00073-09.

13. Wu, W., He, Q. \& Jiang, C. (2008). Magnetic iron oxide nanoparticles: Synthesis and surface functionalization strategies. Nan. Res. Lett. 3(11), 397-415. DOI: 10.1007/s11671-008-9174-9.

14. Mohapatra, M. \& Anand, S. (2010). Synthesis and applications of nanostructured iron oxides/hydroxides-a review. Int. J. Eng. Sci. Technol. 2(8), 127-146. DOI: http://dx.doi. org/10.4314/ijest.v2i8.63846. 
15. Hui, C., Shen, C., Yang, T., Bao, L., Tian, J. \& Ding, H. (2008). Large-scale $\mathrm{Fe}_{3} \mathrm{O}_{4}$ nanoparticles soluble in water synthesized by a facile method. J. Phys. Chem. C 112(30), 11336-11339. DOI: 10.1021/jp801632p.

16. Ahmed, T., Phul, R., Khatoon, N. \& Sardar, M. (2017). Antibacterial efficacy of Ocimum sanctum leaf extract-treated iron oxide nanoparticles. New J. Chem. 41(5), 2055-2061. DOI: 10.1039/C7NJ00103G.

17. Irshad, R., Tahir, K., Li, B., Ahmad, A., Siddiqui, A. \& Nazir, S. (2017). Antibacterial activity of biochemically capped iron oxide nanoparticles: A view towards green chemistry. J. Photochem. Photobiol. B 170(4), 241-246. DOI: 10.1016/j. jphotobiol.2017.04.020.

18. Mahdavi, M., Ahmad, M.B., Haron, M.J., Gharayebi, Y., Shameli, K. \& Nadi, B. (2013). Fabrication and characterization of $\mathrm{SiO}_{2} /(3$-aminopropyl) triethoxysilane-coated magnetite nanoparticles for lead (II) removal from aqueous solution. J. Inorg. Organomet. Polym. Mater. 23(3), 599-607. DOI: 10.1007/ s10904-013-9820-2.

19. Majeed, M.I., Guo, J., Yan, W. \& Tan, B. (2016). Preparation of magnetic iron oxide nanoparticles (MIONS) with improved saturation magnetization using multifunctional polymer ligand. Polymers 8(11), 392-408. DOI: 10.3390/polym8110392.

20. Gotic, M. \& Music, S. (2007). Mossbauer FT-IR and FE SEM investigation of iron oxides precipitated from $\mathrm{FeSO}_{4}$ solutions. J. Nanostruct. 834-836(7), 445-453. DOI: https://doi. org/10.1016/j.molstruc.2006.10.059.

21. Zhang, F., Wang, P., Koberstein, J., Khalid, S. \& Chan, S.W. (2004). Cerium oxidation state in ceria nanoparticles studied with X-ray photoelectron spectroscopy and absorption near edge spectroscopy. Surf. Sci. 563(1-3), 74-82. DOI: https:// doi.org/10.1016/j.susc.2004.05.138.

22. Bavand, R., Yelon, A. \& Sacher, E. (2015). X-ray photoelectron spectroscopic and morphologic studies of $\mathrm{Ru}$ nanoparticles deposited onto highly oriented pyrolytic graphite. Appl. Surf. Sc. 355(5), 279-289. DOI: https://doi.org/10.1016/j. apsusc.2015.06.202.

23. Yamashita, T. \& Hayes, P. (2008). Analysis of XPS spectra of $\mathrm{Fe}^{2+}$ and $\mathrm{Fe}^{3+}$ ions in oxide materials. Appl. Surf. Sci. 254(8), 2441-2449. DOI: https://doi.org/10.1016/j.apsusc.2007.09.063.

24. Rahman, M.M., Khan, S.B., Faisal, M., Rub, M.A., Al-Youbi, M.A. \& Asiri, A.M. (2012). Electrochemical determination of olmesartan medoxomil using hydrothermally prepared nanoparticles composed $\mathrm{SnO}_{2}-\mathrm{Co}_{3} \mathrm{O}_{4}$ nanocubes in tablet dosage forms. Talanta 99(2), 924-931. DOI: https://doi. org/10.1016/j.talanta.2012.07.060.

25. Kon, K. \& Rai, M. (2013). Metallic nanoparticles: mechanism of antibacterial action and influencing factors. J. Comp. Clin. Path. Res. 2(3), 160-2174. DOI: 10.4178/jccph/e2015020.

26. Franci, G., Falanga, A., Galdiero, S., Palomba, L., Rai, M. \& Morelli, G. (2015). Silver nanoparticles as potential antibacterial agents. Molecules 20(5), 8856-8874. DOI: 10.3390/ molecules20058856.

27. Li, H., Chen, Q., Zhao, J. \& Urmila, K. (2015). Enhancing the antimicrobial activity of natural extraction using the synthetic ultrasmall metal nanoparticles. Sci. Rep. 5(5), 11033-11040. DOI: 10.1038/srep11033. 